\title{
As escritas do
jornalismo esportivo
Introduça
}

\author{
Paul Aron \\ Directeur de recherches au FNRS \\ Université libre de Bruxelles \\ Centre Philixte \\ Bélgica \\ paron@ulb.ac.be
}

COM A COLABORAÇÃo DE

LAURENCE ROSIER

Professeure ordinaire Université libre de Bruxelles Centre STRIGES et LADISCO

Bélgica

laurence.rosier@ulb.be

RUADHÁN COOKE

Lecturer

School of Languages, Literatures \& Cultures National University of Ireland, Galway

Irlanda

ruadhan.cooke@nuigalway.ie

\section{MARIE-Ève Thérenty}

Professeure

Université Paul Valéry Montpellier 3 Centre RIRRA21

França marieeve.therenty@sfr.fr

Ruben ARnoldo GonZALEZ

Profesor

Benemerita Universidad Autonoma de Puebla Centro de Estudios en Comunicacion Politica

México

ruben.arnoldo.gonzalez@gmail.com

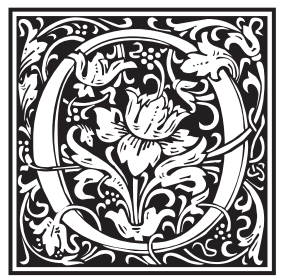

esporte tem ocupado um lugar de destaque na economia da mídia contemporânea. Ele é divulgado tanto pela mídia especializada, quanto pelos meios de comunicação generalistas. Atletas, resultados, conquistas, temporadas de grandes eventos (Copas do Mundo, Jogos Olímpicos ou Paraolímpicos) hoje fazem reconhecidamente parte da chamada "indústria da informação", o que é relativamente recente. O Bell's life in London (1823) foi o primeiro a publicar notícias esportivas, os primeiros periódicos especializados tendo se estabelecido em meados do século XIX (The Field, 1853; Les Sports (1854), jornais sociais; Le Sport nautique, 1860; The Sportsman, 1865). Gradualmente, os resultados esportivos passam a incorporar a pauta de todos os jornais (particularmente com as corridas de cavalos). Se o New York Herald teria sido o primeiro jornal generalista a cobrir sistematicamente o mundo do esporte, o New York World, em 1883, foi pioneiro na constituição de uma equipe de repórteres especializados. A partir do final do século XIX, os títulos esportivos crescem significativamente, passando a incorporar as políticas públicas, não apenas como consequência da democratização do esporte, mas também porque satisfazem os interesses econômicos das indústrias automobilística e do ciclismo. Com o Le Vélo de Pierre Giffard (1892) e seu concorrente L'Auto (1904), de Henry Desgranges, e com a organização do primeiro Tour de France (maior e mais antigo evento de ciclismo do mundo) em jun-

Pour citer cet article, to quote this article, para citar este artigo :

Paul Aron, Laurence Rosier, Ruadhán Cooke, MarieÈve Thérenty, Ruben Arnoldo Gonzalez, « As escritas do jornalismo esportivo », Sur le journalisme, About journalism, Sobre jornalismo [En ligne, online], Vol 10, nº - 2021, 15 décembre - december 15 15 de dezembro.

URL : https://doi.org/10.25200/SLJ.v10.n2.2021.435 
ho/julho de 1903, o esporte adentra a era da mídia, que ainda vigora.

Antes da Primeira Guerra Mundial, o esporte ocupava $6 \%$ do espaço de divulgação dos jornais franceses (Tétard, 2007); após a Segunda Guerra Mundial, passa a ocupar $13,5 \%$ dos jornais parisienses e $30 \%$ da imprensa regional (Seidler, 1964). A partir dessa data, sua participação aumenta constantemente, uma ascensão que se reflete na centralidade dos suplementos esportivos dos jornais ingleses como o The Daily Telegraph, o Daily Mail e o Daily Express. O esporte passa a ser tema de reportagens e crônicas, retransmitido por agências e beneficiando-se de um corpo profissional especializado: jornalistas (inclusive especialistas das diferentes modalidades), fotógrafos, comentaristas de rádio e televisão. Ainda que em meio a uma crise da imprensa, novos jornais são criados e vários sobrevivem ainda hoje; é o caso do Placar (1970) e do Lance! (1997) no Brasil. Paralelamente, uma competição ferrenha se estabelece entre os jornais esportivos - a exemplo dos diários de Madri, As e Marca -, assim como entre os pacotes de canais digitais da TV a cabo, como a ESPN, Eurosport, TVA sports, Canal + sport, etc (no caso da televisão francesa) ${ }^{1}$. No mundo todo, notícias, análises e comentários são construídos e divulgados por diários, semanários e pela Internet.

Mas o jornalismo esportivo ocupa um lugar peculiar na história do jornalismo em geral. O discurso sobre a imprensa esportiva era produzido pelos próprios atores da área, à medida que se desenvolvia a consciência da necessidade de se formar uma subcategoria profissional específica, que geralmente se originava de uma dupla prática, a do/as próprio/as esportistas que passaram a escrever, ou ainda a do/as jornalistas amadore/as de esporte. Essa conjunção, que certamente influenciou a constituição de um modo particular de profissionalização, também é responsável pelo diálogo tardio entre historiadores esportivos e historiadores da imprensa.

Apesar disso, inúmeras pesquisas têm focado na relação entre imprensa e esporte (Raney e Bryant, 2006; Clastres e Méadel, 2007; Combeau-Mari, 2007; Attali, 2009), possibilitando o mapeamento de vastos territórios outrora desconhecidos: o inventário da imprensa esportiva, incluindo a imprensa local e regional, a história dos atores dessa imprensa (jornalistas, fotógrafo/as, escritore/as), as relações entre imprensa esportiva e o mundo econômico e político, e a retórica do discurso esportivo. Em contraponto, esses inventários ainda foram pouco sistematizados: a maioria deles são monografias (sobre um jornal, um esporte, um período ou uma região) que não necessariamente tematizam uma abordagem geral, e menos ainda poéticas específicas. Por isso, muitas questões sobre a escrita esportiva continuam suscitando perguntas, ainda que tenham sido discutidas mais propriamente numa série de obras recentes (Diana e Lochard, 1994; Lowes, 1999; Coelho, 2011; Souanef, 2019), ora em modo prescritivo, ora analítico.

O presente dossiê, composto em parte por textos extraídos das mesas do colóquio de Numapresse (Bruxelas, 24-25 de outubro de 2019) e por artigos submetidos à revista Sur le Journalisme em resposta à chamada de trabalhos lançada em meados de 2020, tem como objetivo aprofundar o conhecimento das escritas do jornalismo esportivo. Para tanto, recorre a certas abordagens disciplinares inusitadas, e a suas técnicas, de modo a renovar a compreensão das temáticas: análise do discurso, história, humanidades digitais e poética do jornalismo.

Com base principalmente em um corpus francófono e lusófono (Brasil), incluindo incursões do mundo anglo-saxão, o dossiê foca a inscrição social do discurso esportivo escrito. De fato, a narrativa esportiva, sempre acompanhada por imagens, manchetes e efeitos de layout, dificilmente pode ser concebida como um desempenho puramente textual. Isso traz à tona uma questão central: como os diferentes elementos da mídia se relacionam e provocam seus efeitos uns com relação aos outros? Como escrever no mundo do ao vivo da rádio e da televisão ou mesmo da Internet? Como a concorrência condiciona as narrativas dos diferentes meios de comunicação? (Schultz, 2007; Moritz, 2014; Leal e Mesquita). De modo mais amplo, a escrita esportiva articula-se tanto com as representações de mundo (nacionalismo, racismo, ativismo, machismo), como com a gestão do território ou do turismo. $\mathrm{O}$ discurso do esporte também pode ser profundamente político, quando remete aos antagonismos coloniais (a exemplo da rivalidade franco-britânica no boxe - Hadjeras), ou engaja o orgulho nacional (como nas derrotas da seleção brasileira de futebol Casagrande). O esporte também é objeto de polêmicas quando aborda (ou deixa de abordar) questões de gênero e transgênero, ou ainda quando transmite ideologias e visões de mundo (Ducournau, Thomas). Todas essas questões revelam que, se a escrita esportiva não pode ser isolada do contexto em que está inserida, ao mesmo tempo, ela continua sendo um motor essencial da atividade jornalística como um todo.

Os contextos organizacionais da escrita esportiva mudaram ao longo do tempo; os espaços de trabalho, as ferramentas, as possibilidades de divulgação e formatação construíram progressivamente diferentes relações do/a jornalista com a escrita (Singer, 2003). Essas condições remetem tanto a fatores externos quanto internos na produção da informação esportiva (Wille). No plano externo, as coberturas inter- 
nacionais de eventos esportivos também devem ser consideradas por levantarem questões sobre uma certa forma de mimetismo nas práticas de escrita, ou mesmo sobre a internacionalização das práticas de narração esportiva. Reunidos em pools, participando das mesmas coletivas de imprensa, distanciado/as do/ as esportistas pela intermediação do/as assessore/as de comunicação, o/as jornalistas esportivo/as precisam desenvolver estratégias específicas para realizar suas produções. É também o caso dos jornais, sendo o esporte alvo de forte competição entre eles. No plano interno, a redação esportiva sempre se referiu a dois níveis distintos: o dos eventos e resultados propriamente ditos, e o dos comentários, investigações ou reportagens que envolvem esses eventos. No entanto, essa distinção não é imutável. Aquilo que poderia ser considerado escrita factual está começando a ser automatizado. A "robotização do jornalismo", que também afeta a cobertura do setor financeiro, tem sido testada na seção de esportes por certas empresas de mídia, alimentando debates não apenas sobre a escrita (sua função, sua importância), mas também sobre o papel do/a jornalista (Danzon-Chambaud, 2020).

Ainda mais recentemente, a Internet abriu espaço para mídias em que o público interage, fornecendo até o próprio material postado e, dessa forma, participando da midiatização do esporte (Singer, 2003; Martins). A escrita (no sentido amplo da palavra), ainda que escape dos quadros profissionais conhecidos, continua participando ativamente das questões sociais e econômicas deste setor de atividade.

As humanidades digitais permitem explorar o imenso corpus de informações disponibilizado on-line nos últimos anos. Também levantam novas questões sobre o lugar do esporte na economia geral da mídia periódica impressa (ritmos de publicação, importância quantitativa, formas específicas de abordagem), sobre os gêneros de jornalismo mobilizados (da reportagem gravada ao semi-ao-vivo, da imersão ao relato fotográfico, da crônica à nota de humor...), sobre a representação do/as esportistas pelas imagens em termos de metaforização heroizante, ou ainda sobre a trajetória do/as jornalistas (Aron).
Do ponto de vista metodológico, como veremos, as escritas do esporte remetem tanto à forma da mídia (suas capas e ilustrações, por exemplo) quanto ao texto em si, em suas diversas modalidades, tais como títulos, registros enunciativos (das entrevistas aos comentários), juízos de valor e ideologias manifestadas (Ducournau; Mendès). A análise do discurso, a semiótica e a sociolinguística têm ajudado a entender como o esporte vem desenvolvendo sua própria linguagem (Caldwell, 2016; Bonnet; Pimenta). O esporte escrito ou falado é enunciado em registros variáveis, da temporalidade da narrativa ao monólogo restituído; do discurso de conivência ao discurso da distância; do registro popular ao pastiche literário (Aron). Esses diferentes discursos dão voz aos múltiplos atores da cena esportiva (dos treinadores aos atletas ou mesmo aos espectadores), retratando as distinções entre os próprios esportes, as tradições discursivas dos diferentes eventos esportivos, e até mesmo o lugar que ocupam no jornal.

Como ilustram as contribuições aqui reunidas, que vão do século XIX ao período contemporâneo, o próprio sentido da palavra "esporte" mudou substancialmente: para além da prática individual que ele continua a designar, mas com conotações muito distintas, remete a todas as áreas da vida social, desde o planejamento urbano, que pensa em sua inclusão na cidade, até a economia globalizada, que coloca em circulação seus atores e as representações que suscita. A escrita esportiva faz parte da própria definição da atividade, participando do seu desenvolvimento e de suas práticas. Esse é o caso, como mostra Hurcombe, do ciclismo desde o final do século XIX; mas também dos esportes de combate, aqui abordados com base nas muitas mídias e redes sociais brasileiras contemporâneas (Martins); ou ainda dos grandes esportes globalizados (Oriard, 1993). São essas estruturas em transformação que a história do jornalismo tenta captar, ora o mais próximo possível daquele/as que as criam, ora com o distanciamento necessário para retratar a evolução de um determinado meio ou de um conjunto de práticas.

\section{Notas}

1. Cf. « Canais de televisão esportivos » na Wikipedia. 


\section{REFERÊNCIAS}

Attali M. (2009), Sport et médias, du XIXe siècle à nos jours, Biarritz, Atlantica, 2009.

Barbeiro, H, Rangel, P. (2006), Manual do Jornalismo Esportivo. São Paulo: Contexto, 2006.

Caldwell, D., Walsh, J., Vine, E. W., \& Jureidini, J. (Eds.). (2016), The discourse of sport: Analyses from social linguistics: Taylor \& Francis.

Clastres P., C. Méadel C. (2007), Le Temps des médias, « La Fabrique des sports », 2007/2 ( n 9 ).

Coelho, P. V. (2011), Jornalismo esportivo. São Paulo: Contexto

Combeau-Mari E. (dir.) (2007), Sport et presse en France (XIXe-XXe siècles), Paris : Éditions le Publieur, 2007.

Danzon-Chambaud S. (2020), « De plus en plus installé, le journalisme automatisé interroge toujours », La Revue des médias, 26 février, https://larevuedesmedias.ina.fr/journalisme-automatise-robot-media

Derèze G., Diana J.-F., Standaert O. (2015), Journalisme sportif. Méthodes d'analyse des productions médiatiques, Bruxelles : de Boeck supérieur.

Diana J.F., Lochard G. (dir.) (1994), Le Sport médiatisé. Du voir au savoir, MédiaMorphoses, $\mathrm{n}^{\circ} 11$, Paris : Ina.
Lowes, M. D. (1999), Inside the sports pages: Work routines, professional ideologies, and the manufacture of sports news, Toronto : University of Toronto Press.

Moritz, B. P. (2014), Rooting for the story: Institutional sports journalism in the digital age. Dissertations - ALL. 171. https://surface.syr.edu/etd/171

Oriard, M. (1993). Reading football. How the popular press created an American spectacle, Chapel Hill, NC: UNC Press.

Raney, A. A., \& Bryant, J. (Eds.). (2006), Handbook of sports and media, New York: Routledge.

Schultz, Brian (September 2007), "Sports journalists who blog cling to traditional values", Newspaper Research Journal 28 (4): 62-76. doi:10.1177/073953290702800406.

Seidler E. (1964), Le sport et la presse, Paris : Armand Colin. Singer, J. B. (2003), «Who are these guys? The online challenge to the notion of journalistic professionalism », Journalism, 4 (2), 139-163.

Souanef S. (2019), Le journalisme sportif : sociologie d'une spécialité dominée, Rennes : Presses universitaires de Rennes, coll. « Res publica ».

Tétart Ph. (2007), Histoire du sport en France, Paris : Vuibert. 